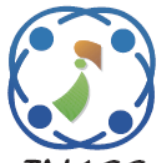

\title{
Robust Takagi Sugeno Fuzzy Models control for a Variable Speed Wind Turbine Based a DFI-Generator
}

\author{
Ahmed Vall Hemeyine $^{1 *} \quad$ Ahmed Abbou $^{1} \quad$ Naoual Tidjani $^{2} \quad$ Mohcine Mokhlis $^{1} \quad$ Anass Bakouri $^{1}$ \\ ${ }^{I}$ Mohammadia School of Engineers (EMI), Mohammed V University in Rabat, Morocco \\ ${ }^{2}$ Djilali Bounaama khemis Miliana University, Science and Technology Faculty, Algeria \\ * Corresponding author's Email: ah.vall_hemeyine@ research.emi.ac.ma
}

\begin{abstract}
This paper proposes a robust fuzzy logic method based on the Takagi-Sugeno fuzzy controller model. In fact, this one is designed in order to control a Doubly-Fed Induction Generator (DFI-Generator) for the variable wind speed turbine. On the one hand, the main aim of the proposed strategy is the real-time tracking of optimal operating point, extracting the maximum output power, and controlling the pitch. This later is applied in order to limit the output power of the system to its nominal value. On the other hand, the proposed controller can extract the maximum of power under variable wind speed. While the existing methods deals with the case of the fixed wind speed. Thus, in this case, the controller can diverge and cause considerable drop of power, whenever the wind speed is changed. Moreover, the proposed control strategy can increase the efficiency and improve the tracking performance of the system. The model is established based on the Parallel Distributed Compensation technique. The stability and tracking analysis properties are ensured by using the Lyapunov approach theory. In addition, the feedback gains of the strategy controller proposed are determined by Linear Matrix Inequalities. A numerical simulation is carried out under Matlab software for comparing the proposed Takagi-Sugeno fuzzy controller with the conventional PI controller. Effectively, these both controllers are applied to controlling the efficiency of the $3 \mathrm{MW}$ DFI-Generator based on Wind Energy Conversion System in order to test their tracking performances and robustness against rapid changes of the reference signal and for testing the proposed controller strategy as well. Indeed, the simulation results prove the robustness of the proposed controller and show the drawbacks of PI controller, which makes high overshoot under the rapid changes of the reference that can reach $20 \mathrm{~A}$ in the worst cases. While, the proposed controller strategy tracks rapidly accurately and without any overshoot, the reference signal.
\end{abstract}

Keywords: Wind energy conversion system, Doubly fed induction generator, Takagi-Sugeno fuzzy model, Fuzzy logic, Vector control, PI control.

\section{Introduction}

Due to the increase of $\mathrm{CO} 2$ emissions, the development and exploitation of renewable energies have grown strongly in recent years [1]. Wind energy is currently considered one of the most promising and important renewable energy sources in the whole world. Mainly, because it is clean energy, costeffective, renewable, friendly to the environment and contributes to minimizing the use of production sources that produce $\mathrm{CO} 2$.

In the past few years, the variable speed wind turbine has become more popular than the fixed speed one. Effectively, because of its variable speed operation, the wind turbine has the ability to extract maximum power from wind [2]. Generally, most of the variable speed wind turbines use three types of generators, which are the Permanent Magnet Synchronous Generator (PMSG), Squirrel-Cage Induction Generator (SCIG), Wound-Field Synchronous Generator (WFSG) and Double Field Induction-generator (DFI-Generator).

Actually, the DFI-Generator is widely used for variable speed wind turbines' applications. These machines are mostly used because of their efficiency and many other qualities, such as reduced power losses, simplicity to control, cost and robustness and 
the ability to work at variable speed $( \pm 33 \%)$ around the synchronous speed [3]. In addition, the DFIGenerator is robust and requires less maintenance.

Fig. 1 shows the system studied in this paper that is based on DFI-Generator.

The quality of the energy produced using wind turbines does not depend only on the wind, but it depends also on the control strategy used. In this context, many control strategies have been proposed and developed in the last years. In fact, there are the Linear Control Systems such as PI Controller Based on Vector Control, this method lacks robustness because of the machine's internal parameters' variations.

The robust polynomial RST controller, that is proposed in, is considered more efficient than the PI controller. In fact, the RST controller can reduce the disturbance effect in the reference signal tracking [4]. While the Active Disturbance Rejection Control (ADRC) can compensate for the internal and external disturbances by the help of the Extended State Observer (ESO) used. However, the ADRC controller is not robust against the change of the system parameters because of the PI controller used. In fact, the adjustment of the PI controller parameters is made only for a system with constant parameters. Thus, these parameters become wrong when the system parameters change.

The Nonlinear Controllers such as the Backstepping [5], the sliding mode controller and the Fuzzy logic controllers [6]. These controllers are robust against the parameters' variations. However, their major drawback is the implementation difficulties. Also, the major inconvenient of the sliding mode controller is the effect of chattering caused by the discontinued part of the control [7].

Consequently, as discussed before, the Backstepping is the nonlinear controller that has been developed to take into account the parameters change. But this controller is characterized by the difficulty and complexity of implementation which is the main disadvantage of these kinds of controllers. Therefore,

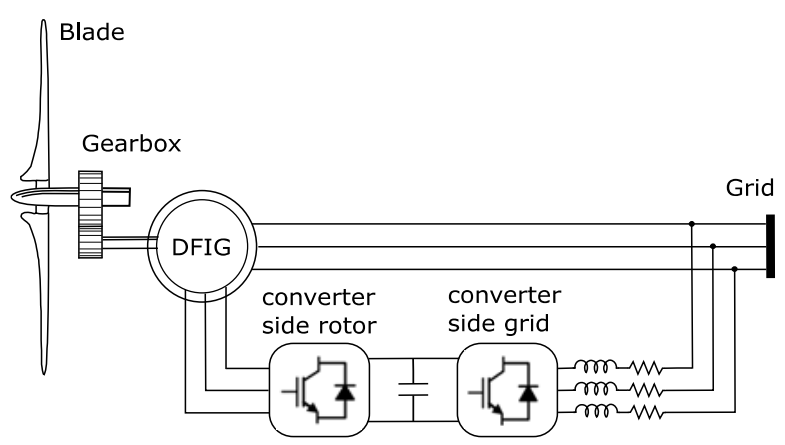

Figure.1 Wind energy conversion system configuration to deal with this, the Takagi-Sugeno fuzzy model is proposed in this study.

The T-S fuzzy models are used because they are easier to design and implement. Also, they are characterized by their tracking performances better than the PI controller, the RST and the ADRC controller as well. Also, this controller is more accurate than the sliding the sliding mode controller, this one which remains oscillating permanently around the reference signal. In fact, the T-S fuzzy models just consist of decomposing the nonlinear system model in a set of linear subsystems that allow constructing the controller based on the Parallel Distributed Compensation (PDC) technique.

Moreover, the stability and tracking analysis properties are demonstrated by using the Lyapunov approach theory. Also, the feedback gains of the strategy controller proposed are determined by using the Linear Matrix Inequalities [8]. Finally, the T-S fuzzy model is compared with the conventional PI controller and the ADRC controller in order to show its tracking performances (rapidity and accuracy). Also, to show its robustness against the rapid changes of the reference signal.

This work is organized as follows. The second section is dedicated to the modeling of the Wind Energy Conversion system and the DFI-generator with the MPPT control strategy and Pitch control. While the third section explains the proposed control strategy of WECS in detail. The simulation results are discussed in the next section in order to demonstrate the performance and robustness of the proposed Takagi-Sugeno Fuzzy control model and compare this one to the conventional PI controller. Finally, the conclusion is presented in the last section.

\section{WECS model}

\subsection{Turbine model}

The aerodynamic power extracted from the wind is given by the following expression $[6,7]$ :

$$
P_{w}=0.5 C_{p}(\lambda, \beta) \rho \pi R^{2} V_{w}^{3}
$$

Where $(\rho)$ is the air density $\left(1.225 \mathrm{Kg} / \mathrm{m}^{3}\right),(R)$ is the radius of the turbine blades, $\left(V_{w}\right)$ is the wind speed $(\mathrm{m} / \mathrm{s}),\left(C_{p}\right)$ is the power coefficient which depends on the pitch angle $(\beta)$, and $(\lambda)$ is the speed ratio. These parameters are defined as follows:

$$
\lambda=\frac{R \cdot \Omega_{t}}{V_{w}}
$$




$$
\begin{gathered}
C_{p}(\lambda, \beta)=C_{1}\left(\frac{C_{2}}{\lambda_{i}}-C_{3} \beta-C_{4}\right) \exp \left(-\frac{C_{5}}{\lambda_{i}}\right) \\
+C_{6} \lambda
\end{gathered}
$$

With

$C_{1}=0.5176, C_{2}=116, C_{3}=0.4, C_{4}=5, C_{5}=$ 21 , and $C_{6}=0.0068$

Where

$$
\frac{1}{\lambda_{i}}=\frac{1}{\lambda+0.08 \cdot \beta}-\frac{0.035}{\beta^{3}+1}
$$

The variation of the power coefficient as a function of $\lambda$ for different values of the pitch angle $\beta$, in the case of a variable speed, is illustrated in Fig. 2. The maximum value of $C_{p}(\lambda, \beta)$ is $C_{p \max }=0.48$ obtained for $\lambda_{\text {opt }}=8.1$ and $\beta=0$ [9].

To produce the power from the wind energy, we need to adapt the wind turbine speed to the electrical machine one, to do that, we have used a gearbox, with a gear ratio noted $G$, is installed. The mechanical speed and the generator torque are presented in Eq. (5) and Eq. (6).

$$
\begin{gathered}
\Omega_{m}=G \Omega_{t} \\
T_{e m}=\frac{T_{t}}{G}
\end{gathered}
$$

In order to extract the maximum power for an average and low wind speed, the MPPT strategy is used. Effectively, the objective, behind using this strategy, is to maximize the power captured by the turbine rotor. However, to achieve this objective, it is necessary to control the electromagnetic torque $T_{e m}$ of the DFI-Generator so as to fix the DFIG rotation speed at the rotation speed reference. Indeed, this latter can be expressed as described in the following equation:

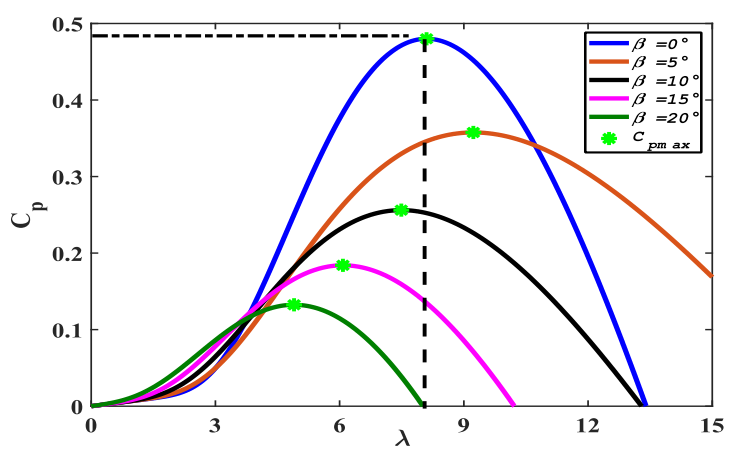

Figure.2 Turbine power coefficient

$$
\Omega_{t-o p t}=\frac{V_{w} \cdot \lambda_{o p t}}{R}
$$

In this paper, the maximal speed ratio is maintained at an optimal value that is $C_{p \max }=0.48$, and which is obtained for $\lambda_{\text {opt }}=8.1$, while $\beta$ must be equal to 0 in order to extract the maximum power. So, when these conditions are true, the maximum mechanical power extracted from the wind can be expressed in the following form:

$$
P_{m e c}=\frac{\pi \rho R^{5} C_{p m a x} \Omega_{m e c}^{3}}{2 \lambda_{o p t}^{3}}
$$

The reference torque $T_{\text {em-ref }}$ is given by the following equation:

$$
T_{e m-r e f}=\frac{\pi \rho R^{5} C_{p m a x} \Omega_{m e c}^{2}}{2 \lambda_{o p t}^{3}}
$$

If the wind speed is too high, the turbine rotation speed has to be limited to a maximum value in order to avoid the possible damage in the turbine structure. For this, the system controller, which is the pitch control, is used. As a result, the electrical energy produced by the wind turbine can be kept constant and equal to the nominal value.

\subsection{DFI-generator control using existing controllers}

The model of the DFI-Generator is described in the (dq) reference frame by the following set of equations.

$$
\left\{\begin{array}{l}
V_{s d}=R_{s} I_{s d}+\frac{d \varphi_{s d}}{d t}-\omega_{s} \varphi_{s q} \\
V_{s q}=R_{s} I_{s q}+\frac{d \varphi_{s q}}{d t}+\omega_{s} \varphi_{s d} \\
V_{r d}=R_{r} I_{r d}+\frac{d \varphi_{r d}}{d t}-\omega_{r} \varphi_{r q} \\
V_{r q}=R_{r} I_{r q}+\frac{d \varphi_{r q}}{d t}+\omega_{r} \varphi_{r d}
\end{array}\right.
$$

The stator and rotor flux are given as:

$$
\left\{\begin{array}{l}
\varphi_{s d}=L_{s} I_{s d}+L_{m} I_{r d} \\
\varphi_{s q}=L_{s} I_{s q}+L_{m} I_{r q} \\
\varphi_{r d}=L_{r} I_{r d}+L_{m} I_{s d} \\
\varphi_{r q}=L_{r} I_{r q}+L_{m} I_{s q}
\end{array}\right.
$$




$$
T_{e m}=P \frac{M}{L_{s}}\left(I_{r d} \varphi_{s q}-I_{r q} \varphi_{s d}\right)
$$

The system mechanical equation is:

$$
J \frac{d \Omega_{m}}{d t}=T_{m}-T_{e m}-f \Omega_{m}
$$

Moreover, to be able to control the DFI-Generator easily, we will achieve independent control of active and reactive power by the stator flux orientation. The principle is to align the stator flux along the d-axis of the rotating frame $[8,11]$. For medium and highpower machines used in wind energy conversion systems, the stator resistance Rs can be neglected, the electrical equations of the DFI-Generator model are expressed as below:

$$
\varphi_{s d}=\varphi_{s} \text { And } \varphi_{s q}=0
$$

In addition, the stator voltage equations are reduced to:

$$
\left\{\begin{array}{l}
V_{s d}=0 \\
V_{s q}=V_{s}=\omega_{s} \varphi_{s}
\end{array}\right.
$$

The active and reactive powers at the stator side are written as

$$
\left\{\begin{array}{c}
P_{s}=V_{s d} I_{s d}+V_{s q} I_{s q}=-V_{s} \frac{L_{m}}{L_{s}} I_{r q} \\
Q_{s}=V_{s q} I_{s d}-V_{s d} I_{s d}=\frac{V_{s}^{2}}{\omega_{s} L_{s}} \\
-V_{s q} \frac{L_{m}}{L_{s}} I_{r d}
\end{array}\right.
$$

Thereafter, we establish the equations showing the relationship between the rotor voltages and rotor currents:

$$
\begin{gathered}
V_{r d}=R_{r} i_{r d}+L_{r} \sigma \frac{d I_{r d}}{d t}-g L_{r} \sigma \omega_{s} I_{r q} \\
V_{r q}=R_{r} i_{r d}+L_{r} \sigma \frac{d I_{r q}}{d t}+g \omega_{s} L_{r} \sigma I_{r d} \\
+\frac{L_{m} V_{s}}{L_{s}}
\end{gathered}
$$

\subsubsection{PI controller design}

The proportional-integral (PI) controller is still the most commonly used for controlling the wind

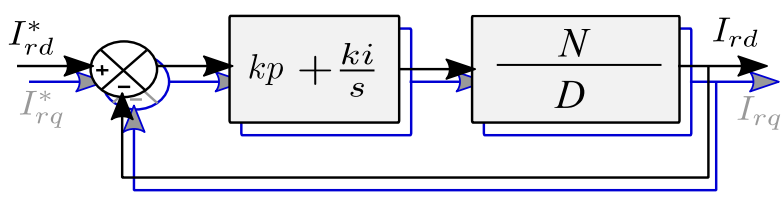

Figure. 3 block diagram of the PI controller

turbine based on a DFI-Generator, thanks to its simplicity to design and implement.

In this study, two PI controllers are used in order to control both axes $\mathrm{d}$ and $\mathrm{q}$, which allows controlling the active and reactive powers. Thus, this can eliminate the gap between the measured active and reactive power and the desired references of power. Fig. 3 shows the block diagram of the PI controller. Here, $K_{p}$ and $K_{i}$ present respectively the proportional and integral gains.

The quotient (N/D) represents the transfer function to be controlled, where $\mathrm{N}$ and $\mathrm{D}$ are presently defined as follows:

$$
\left\{\begin{array}{l}
N=\left(L_{s} R_{r}+s \cdot L_{s}\left(L_{r}-\frac{L_{m}^{2}}{L_{s}}\right)\right) \\
D=\omega_{s} \cdot \varphi_{s} \cdot L_{m}
\end{array}\right.
$$

The pole-compensation method is chosen in order to calculate the parameters of PI regulator because it is simple to implement and gives a good performance. The time response $\left(\tau_{r}\right)$ is fixed to $1 m s$ in order to increase the rapidity of the systems:

$$
\left\{\begin{array}{l}
K_{p}=\frac{L_{s}\left(L_{r}-\frac{L_{m}^{2}}{L_{s}}\right)}{\tau_{r} \cdot \omega_{s} \cdot \varphi_{s} \cdot L_{m}} \\
K_{i}=\frac{L_{s} R_{r}}{\tau_{r} \cdot \omega_{s} \cdot \varphi_{s} \cdot L_{m}}
\end{array}\right.
$$

\subsubsection{ADRC controller design}

Active Disturbance Rejection Control (ADRC) is a robust command based on the extension of the model system by a state observer to estimate what the user cannot master in the mathematical model of the system to control. This state observer dubbed Extended State Observer (ESO) allows estimating all real disturbance and modeling uncertainties [8].

In this part, we are interested in controlling the power of DFI-Generator by the ADRC controller. We only have the active power is controlled through the $\mathrm{q}$-axis rotor current and d-axis rotor current control the reactive power. We are implemented two ADRC controllers control loops of rotor currents $I_{r d}$ and $I_{r q}$. 


$$
\left\{\begin{array}{c}
\frac{d I_{r d}}{d t}=-\frac{R_{r}}{\sigma L_{r}} I_{r d}+\omega_{r} I_{r q}+\frac{1}{\sigma L_{r}} V_{r d} \\
\frac{d I_{r d q}}{d t}=-\frac{R_{r}}{\sigma L_{r}} I_{r q}-\omega_{r} I_{r d}+\frac{1}{\sigma L_{r}} V_{r q} \\
-\frac{V_{s} L_{M}}{\sigma L_{r} L_{s} \omega_{s}} V_{r q}
\end{array}\right.
$$

The expressions shown in (Eq. 20) can be put in the following form:

$$
\frac{d I_{r d q}}{d t}=f\left(I_{r d q}, d, t\right)+b_{0} u(t)
$$

Where:

$$
\left\{\begin{array}{l}
f\left(I_{r d}, d, t\right)=-\frac{R_{r}}{\sigma L_{r}} I_{r d}+\omega_{r} I_{r q} \\
u(t)=V_{r d} \quad ; \quad b_{0}=\frac{1}{\sigma L_{r}}
\end{array}\right.
$$

With

$$
\left\{\begin{array}{r}
f\left(I_{r q}, d, t\right)=-\frac{R_{r}}{\sigma L_{r}} I_{r q}-\omega_{r} I_{r d} \\
-\frac{V_{s} \omega_{r} L_{m}}{\sigma L_{r} L_{s} \omega_{s}} \\
u(t)=V_{r q} ; \quad ; \quad b_{0}=\frac{1}{\sigma L_{r}}
\end{array}\right.
$$

Where $f\left(I_{r d}, d, t\right), f\left(I_{r q}, d, t\right)$ are the total external and internal disturbances those respectively influencing currents of rotor $\left(I_{r d}, I_{r q}\right)$. While $u_{r d}, u_{r q}$ are the control inputs of the rotor currents' loops. Fig. 4 presents structure of ADRC controller.

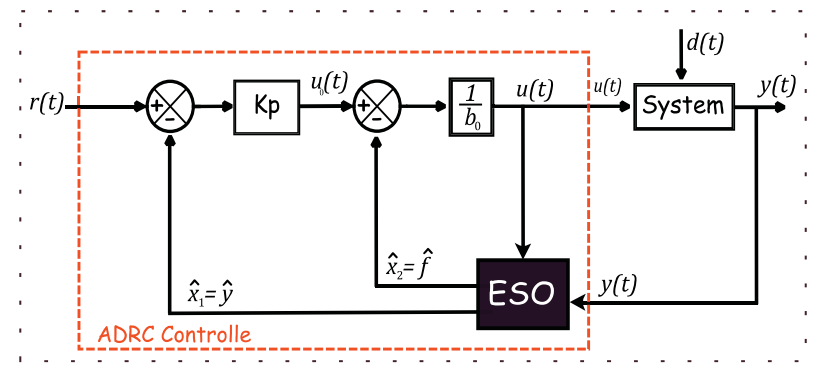

Figure.4 Structure of ADRC controller

\subsection{DFI-Generator control using proposed controller}

\subsubsection{DFI-Generator Takagi-Sugeno fuzzy model}

The state space of the Double Feed Induction Generator dynamics model is expressed by the following equations [11]:

$$
\left\{\begin{array}{l}
\dot{x}(t)=A x(t)+B u(t) \\
y(t)=C x(t)
\end{array}\right.
$$

With

$$
\begin{gathered}
\left\{\begin{array}{l}
x(t)=\left[\begin{array}{ll}
I_{r d} & I_{r q}
\end{array}\right]^{T} \\
u(t)=\left[\begin{array}{ll}
V_{r d} & V_{r q}
\end{array}\right]^{T} \\
y(t)=\left[\begin{array}{ll}
P_{s} & Q_{s}
\end{array}\right]^{T}
\end{array}\right. \\
A=\left[\begin{array}{cc}
-R_{r} /\left(L_{r} \sigma\right) & g w_{s} \\
-g w_{s} & -R_{r} /\left(L_{r} \sigma\right)
\end{array}\right] \\
B=\left[\begin{array}{cc}
1 /\left(L_{r} \sigma\right) & 0 \\
0 & 1 /\left(L_{r} \sigma\right)
\end{array}\right] \\
C=\left[\begin{array}{c}
0 \\
-g V_{s} L_{m} / L_{s}
\end{array}\right]
\end{gathered}
$$

Where $\quad V_{r}$ : is rotor voltage, $V_{S}$ : is stator voltage, $I_{r}$ : is rotor current, $I_{S}$ : is stator current, $R_{S}$ : is stator resistance, $R_{r}$ : is rotor resistance, $L_{r}$ : is rotor leakage inductance, Ls :is stator leakage inductance. $L_{m}$ : is mutual inductance, $\omega_{s}$ : is stator pulsation.

With the leakage coefficient $\sigma$ is given by:

$$
\sigma=1-\frac{L_{m}^{2}}{L_{r} L_{s}}
$$

The sector of nonlinearities of $\omega_{s}(t)$ is bounded:

$$
\underline{\omega_{s}} \leq \omega_{s}(t) \leq \overline{\omega_{s}}
$$

Thus, the premise variable then becomes:

$$
\omega_{s}(t)=F_{1} \overline{\omega_{s}}+F_{2} \underline{\omega_{s}}
$$

Where, $F_{1}, F_{2}$ denote the grade of membership functions that can be defined as follows:

$$
F_{1}=\frac{\omega_{s}(t)-\underline{\omega_{s}}}{\overline{\omega_{s}}-\underline{\omega_{s}}} ; F_{2}=\frac{\overline{\omega_{s}}-\omega_{s}(t)}{\overline{\omega_{s}}-\underline{\omega_{s}}}
$$


The fuzzy model for a dynamic system is described by the finite set of fuzzy IF ... THEN rules as follow [12]:

Rule 1: if $\omega_{s}(t)$ is $F_{1}$ then:

$$
\left\{\begin{array}{l}
\dot{x}(t)=A_{1} x(t)+B_{1} u(t) \\
y(t)=C_{1} x(t)
\end{array}\right.
$$

Rule 2: if $\omega_{s}(t)$ is $F_{2}$ then:

$$
\left\{\begin{array}{l}
\dot{x}(t)=A_{2} x(t)+B_{2} u(t) \\
y(t)=C_{2} x(t)
\end{array}\right.
$$

Where,

$$
\begin{gathered}
A_{1}=\left[\begin{array}{cc}
-R_{r} /\left(L_{r} \sigma\right) & g \bar{w}_{s} \\
-g \bar{w}_{s} & -R_{r} /\left(L_{r} \sigma\right)
\end{array}\right] \\
A_{2}=\left[\begin{array}{cc}
-R_{r} /\left(L_{r} \sigma\right) & g \underline{\omega_{s}} \\
-g \underline{\omega_{s}} & -R_{r} /\left(L_{r} \sigma\right)
\end{array}\right] \\
B_{1}=B_{2}=\left[\begin{array}{cc}
1 /\left(L_{r} \sigma\right) & 0 \\
0 & 1 /\left(L_{r} \sigma\right)
\end{array}\right] \\
C_{1}=C_{2}=\left[\begin{array}{c}
0 \\
-g V_{s} L_{m} / L_{s}
\end{array}\right]
\end{gathered}
$$

The global fuzzy model is inferred as follows:

$$
\dot{x}(t)=\sum_{i=1}^{2} h_{i}\left(\omega_{S}(t)\right)\left\{A_{i} x(t)+B_{i} u(t)\right\}
$$

Where

$$
h_{i}\left(\omega_{s}(t)\right)=\frac{F_{i}\left(\omega_{s}(t)\right)}{\sum_{i=1}^{2} F_{i}\left(\omega_{s}(t)\right)}
$$

It is obvious that:

$$
\sum_{i=1}^{2} h_{i}\left(\omega_{s}(t)\right)=1 \text { with } h_{i}\left(\omega_{s}(t)\right) \geq 0
$$

\section{Tracking DFI-generator control of active and reactive power}

\subsection{TS Fuzzy Controller based Power Control}

Most of the existing research deals with the efficiency of the T-S model system. However, these only make it possible to guarantee the return of the non-linear system to a point of equilibrium starting from non-zero initial conditions [13].

$$
\tilde{x}(t)=x(t)-x_{o p}(t)
$$

With Eq. (42) can be defined as the tracking error. Its time derivative is given by:

$$
\dot{\tilde{x}}(t)=\dot{x}(t)-\dot{x}_{o p}(t)
$$

The purpose is to drive the state variable to follow the optimal reference, so the tracking error must converge to 0 :

$$
x(t)-(t) \rightarrow 0, \quad t \rightarrow \infty
$$

By replacing the term of Eq. (38), into Eq. (42), this latter becomes:

$$
\begin{aligned}
\dot{\tilde{x}}(t)=\sum_{i=1}^{2} h_{i}( & \left.\omega_{s}(t)\right)\left\{A_{i} \tilde{x}(t)\right. \\
& \left.+B_{i} u(t)+A_{i} x_{o p}(t)\right\} \\
& -\dot{x}_{o p}(t)
\end{aligned}
$$

Introducing the new control variable $\tau(t)$ that satisfy the following relation [14]:

$$
\begin{aligned}
& \sum_{i=1}^{2} h_{i}\left(\omega_{s}(t)\right) B_{i} \tau(t) \\
& =\sum_{i=1}^{2} h_{i}\left(\omega_{s}(t)\right)\left\{B_{i} u(t)+A_{i} x_{o p}(t)\right\} \\
& -\dot{x}_{o p}(t)
\end{aligned}
$$

The Takagi-Sugeno fuzzy controllers is performed through the parallel distributed compensation technique Controller rule $i=1,2$

$$
\dot{\tilde{x}}(t)=\sum_{i=1}^{2} h_{i}\left(\omega_{S}(t)\right)\left\{A_{i} \tilde{x}(t)+B_{i} \tau(t)\right\}
$$

The overall Parallel Distributed Compensation controller is inferred as follows $[12,14]$ :

$$
\tau(t)=-\sum_{j=1}^{\tau} h_{j}\left(\omega_{s}(t)\right) K_{j} \tilde{x}(t)
$$

Combining Eq. (48) with Eq. (46), the closed-loop fuzzy system is written as: 


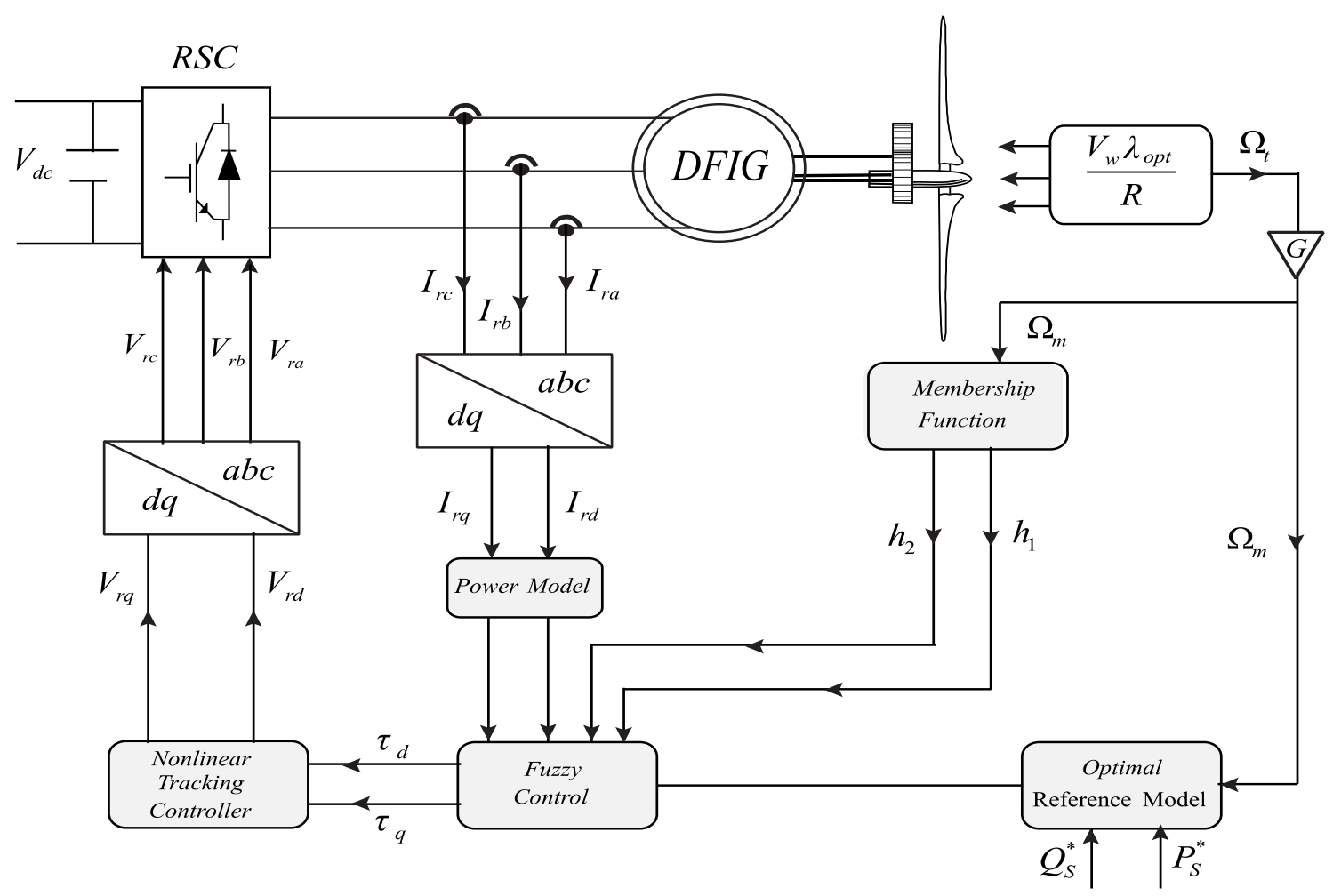

Figure.5 WECS based on DFI-generator with the control strategy proposed

$$
\dot{\tilde{x}}(t)=\sum_{i=1}^{2} \sum_{j=1}^{2} h_{j}\left(\omega_{s}(t)\right) h_{j}\left(\omega_{s}(t)\right) G_{i j} \tilde{x}(t)
$$

Where,

$$
G_{i j}=A_{i}-B_{i} K_{j}
$$

In order to determine the conditions stability of the TS fuzzy controllers, the Lyapunov approach is considered. The Takagi Sugeno fuzzy system Eq. (48), is stable if the following LMI hold are satisfied:

$$
\begin{aligned}
& \text { For } i=j \\
& \qquad Q A_{i}^{T}+A_{i} Q-M_{i}^{T} B_{i}^{T}-B_{i} M_{i}+\alpha Q<0
\end{aligned}
$$

For $i \neq j$

$$
Q A_{i}^{T}+A_{i} Q-M_{j}^{T} B_{i}^{T}-B_{i} M_{j}+\alpha Q<0
$$

Where

$$
Q=P^{-1}, K_{j}=M_{j} Q^{-1}
$$

And $\alpha$ is a positive scalar.

\subsection{Optimal reference controller and nonlinear tracking control}

Using the Eq. (44) to establish the optimal reference controller and the nonlinear tracking controller:

$$
\begin{aligned}
& \sum_{i=1}^{2} h_{i}\left(\omega_{s}(t)\right) B_{i} \tau(t) \\
& =\sum_{\substack{i=1 \\
-\dot{x}_{o p}}} h_{i}\left(\omega_{s}(t)\right)\left\{B_{i} u(t)+A_{i} x_{o p}(t)\right\}
\end{aligned}
$$

It can be noticed that

$$
A=\sum_{i=1}^{2} h_{i} A_{i} \text { And } B=\sum_{i=1}^{2} h_{i} B_{i}
$$

Therefore Eq. (54) can be rewritten in the following form:

$$
B(u(t)-\tau(t))=A\left(\omega_{s}\right) x_{o p}(t)-\dot{x}_{o p}(t)
$$


Using Eq. (55) to the DFI-Generator model, the following matrix form can be obtained:

$$
\begin{gathered}
{\left[\begin{array}{cc}
1 /\left(L_{r} \sigma\right) & 0 \\
0 & 1 /\left(L_{r} \sigma\right)
\end{array}\right]\left[\begin{array}{l}
V_{d}-\tau_{d} \\
V_{q}-\tau_{q}
\end{array}\right]=} \\
-\left[\begin{array}{cc}
-\frac{R_{r}}{L_{r} \sigma} & g w_{s} \\
-g w_{s} & -\frac{R_{r}}{L_{r} \sigma}
\end{array}\right]\left[\begin{array}{l}
I_{d r o p} \\
I_{\text {qrop }}
\end{array}\right]-\frac{d}{d t}\left[\begin{array}{l}
I_{\text {drop }} \\
I_{\text {qrop }}
\end{array}\right]
\end{gathered}
$$

Using the Eq. (56), the nonlinear tracking controller is obtained as follows:

$$
\left\{\begin{array}{c}
V_{r d}=\tau_{d}+R_{r} I_{\text {drop }}-g L_{r} \sigma \omega_{s} I_{\text {qrop }} \\
+L_{r} \sigma I_{\text {qrop }} \\
V_{r q}=\tau_{q}+g L_{r} \sigma \omega_{s} I_{d r o p}+R_{r} I_{\text {qrop }} \\
+\frac{g V_{s} L_{m}}{\sigma L_{r} L_{s}}+L_{r} \sigma I_{\text {qrop }}
\end{array}\right.
$$

Fig. 5 presents the Wind Energy Conversion System based on DFI-Generator with the control strategy proposed.

\section{Simulation results}

In this section, the proposed control strategy is evaluated and compared in order to test its tracking performances under Matlab software. The system parameters are listed in Tables 1 and 2.

Fig. 6 shows the profile of the wind speed applied to the turbine, which varies below and above the nominal speed $V_{n}=12 \mathrm{~m} / \mathrm{s}$. This variation makes it possible to observe the operation of the wind turbine in two modes:

- MPPT mode when the wind speed is lower than the nominal wind speed, therefore the wind turbine can generate the maximum power according to the specific wind speed.

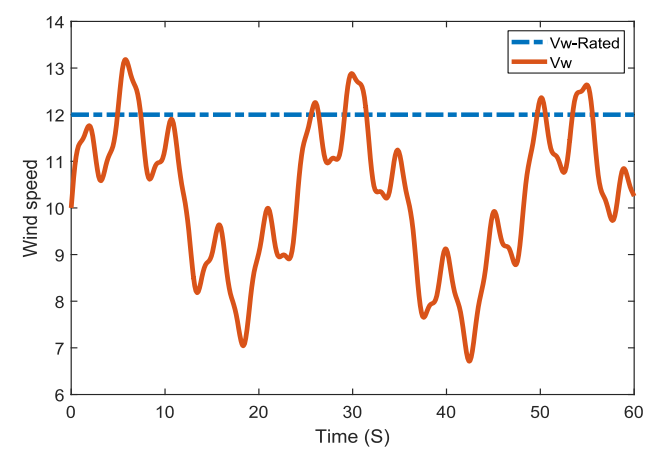

Figure.6 Wind speed $\left(V_{w}\right)$ profile.

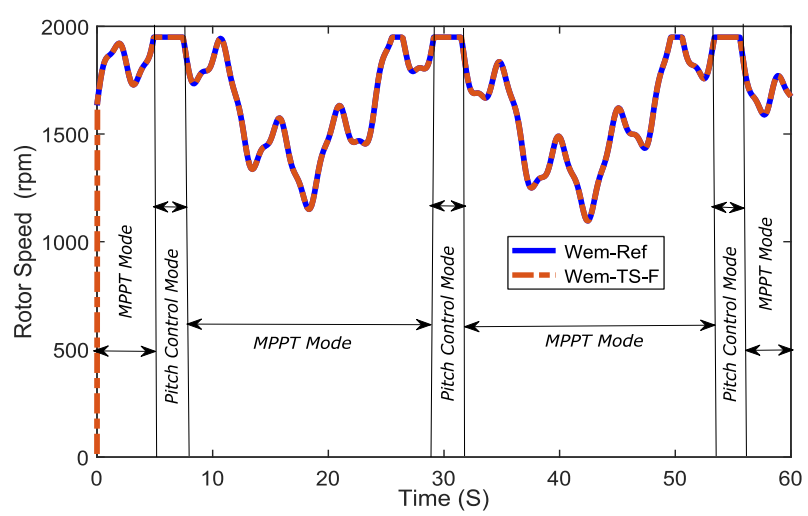

Figure.7 Rotor speed $\left(\mathrm{W}_{\mathrm{em}}\right)$

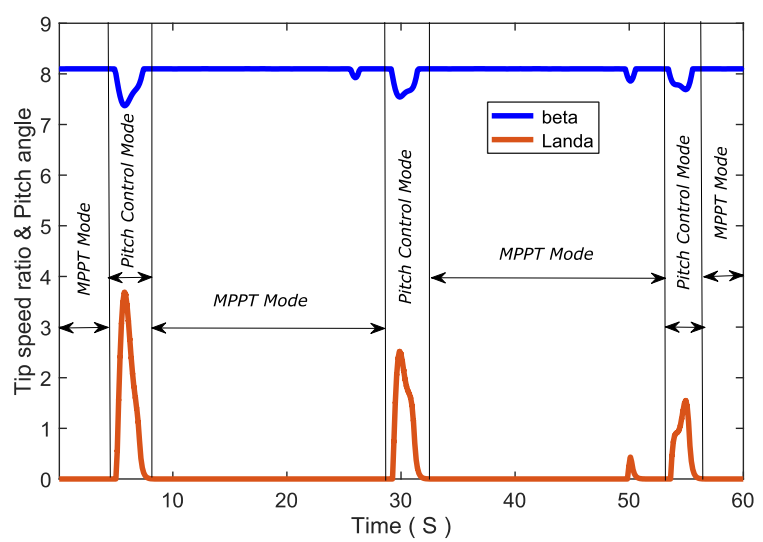

Figure. 8 Speed ratio and pitch angle

- Pitch control mode, if the wind speed exceeds the nominal speed, the pitch control mode is activated in order to limit the captured wind energy to its nominal value.

Fig. 7 presents the mechanical speed of the DFIGenerator $\left(W_{e m}\right)$. It can be noticed that the turbine is well adapted to the wind variation thanks to the MPPT control strategy and Pitch Control. Moreover, the speed profile has a similar shape as the wind variation.

Fig. 8 shows that the specific speed $\lambda$ is equal to its optimal value $\lambda_{\text {opt }}=8.1$ in MPPT mode and degrades in Pitch control mode, while the orientation angle $\beta$ is equal to 0 in MPPT mode and varies according to the wind speed in Pitch control mode to limit the power extracted to the nominal value of the DFI-Generator.

As can be seen in Fig. 9, the power of the coefficient $C_{p}$ is equal to 0.48 for the MPPT mode and inferior to 0.48 for the pitch control mode.

Fig. 10 presents the Mechanical power of the Turbine $\left(P_{m}\right)$. It can be noticed that the turbine is well adapted to the wind variation thanks to the MPPT control strategy and Pitch Control used. 


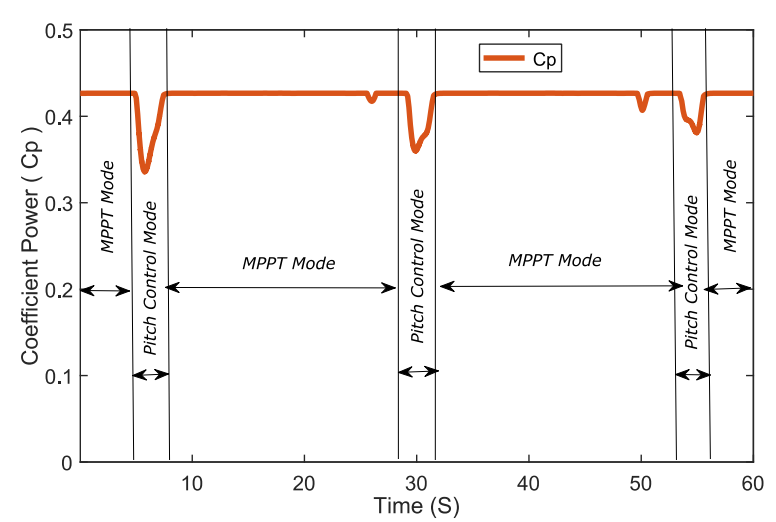

Figure. 9 Coefficient of performance $C_{p}$

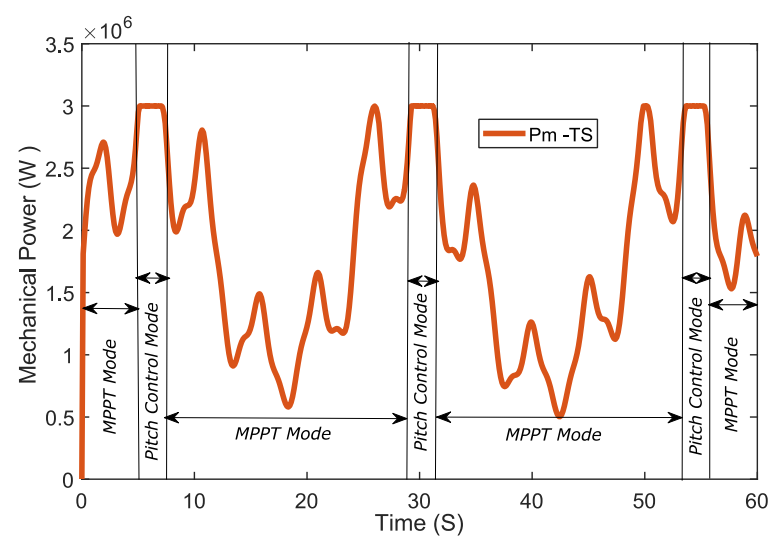

Figure.10 Mechanical power

Fig. 11 presents the active power which follows the evolution of the wind speed. The rated power $(3 \mathrm{MW})$ is obtained at the rated wind speed $12 \mathrm{~m} / \mathrm{s}$ and the specific speed, $N_{m}=1950 \mathrm{rpm}$. The sign of the active power is negative, which means that the DFI-Generator produces energy and distributes it to the grid.

Moreover, Fig. 11 depicts the comparison between two existing controllers, which are PI and ADRC controllers, and the proposed TS-Fuzzy controller. As can be seen in this figure, The PI controller is not accurate, while the ADRC makes small overshoot during small laps of times, then tracks accurately the reference signal, whereas, the proposed controller is accurate and doesn't make any overshoot, which proves its robustness against rapid changes of the signal reference.

Fig. 12 shows that the reactive power is properly regulated at the desired value 0 during the time intervals $[0 s, 200 s]$ and $[40 s, 60 s]$ and tracks accurately and rapidly the signal reference of power. So, it can be noted that the power factor is unity during this interval of time. In addition, to test the proposed controller robustness, the rotor resistance $R_{r}$ is considered increased 2 times more than its initial value. It can be concluded that the TS-Fuzzy controller is more robust than the existed PI and ADRC controllers. Therefore, the proposed controller is able to reject perturbations.

Fig. 13 and Fig. 14, depicts the q-axis and d-axis currents respectively. It can be noticed that, by using the proposed controller, these rotor currents perfectly follow their references without overshooting. Also, the TS-Fuzzy controller proposed has the tracking performances better than the PI and ADRC controllers.

Fig. 15 shows that the rotor currents $I_{r-a b c}$, of the DFI-Generator, are three-phase and in sinusoidal form.

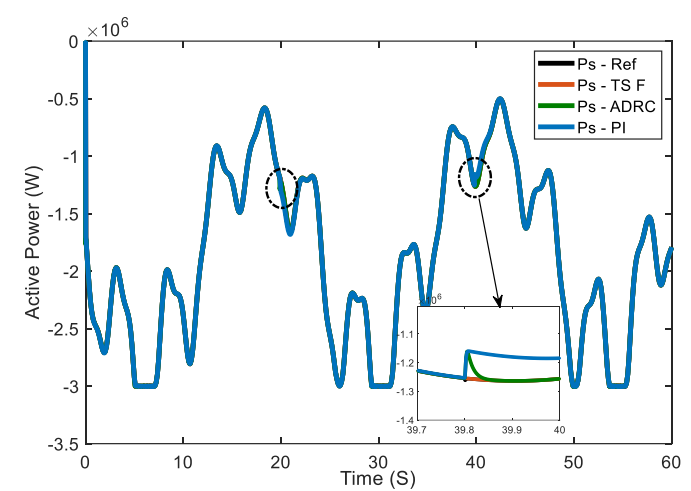

Figure.11 Active power $\left(P_{s}\right)$ of the DFI-generator

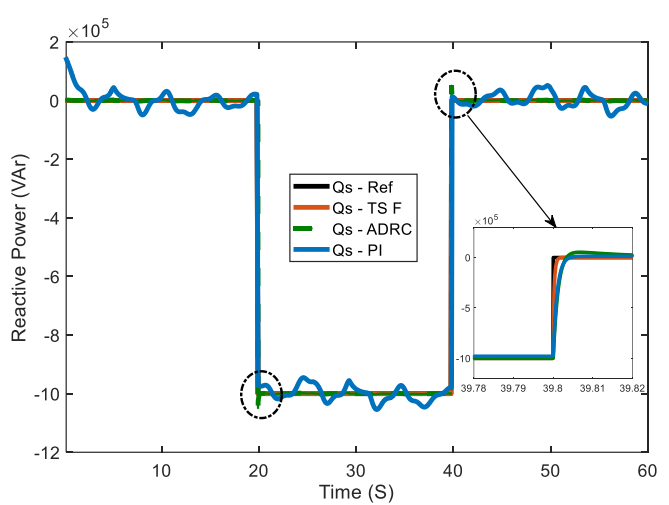

Figure.12 Reactive power (Qs) of the DFI-generator

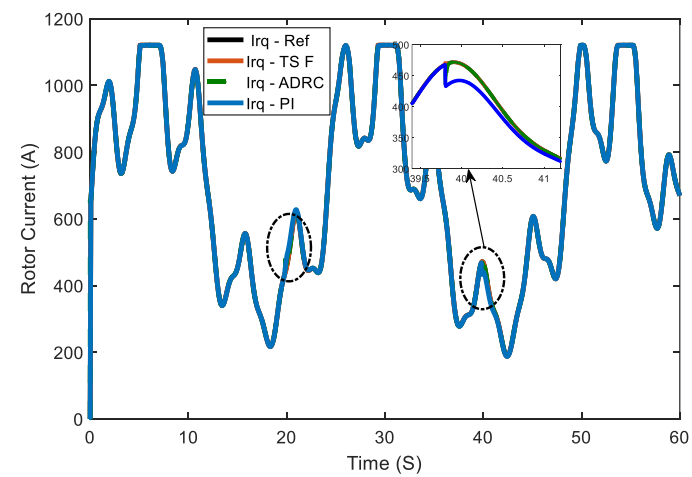

Figure.13 Rotor current $\left(I_{r q}\right)$ 


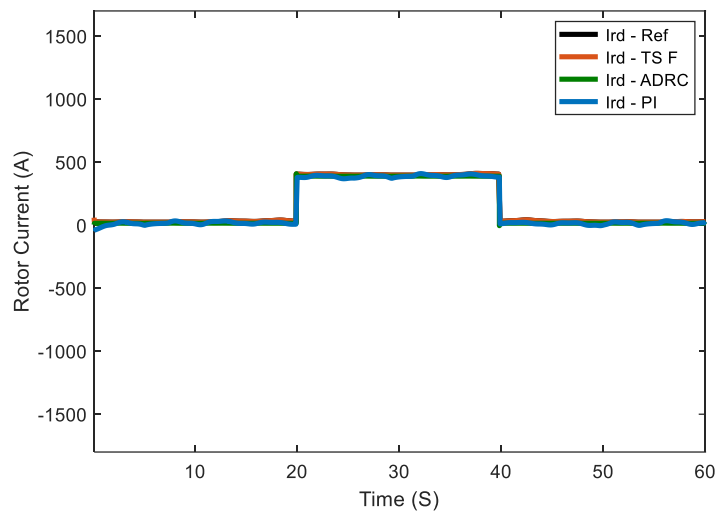

Figure.14 Rotor current $\left(I_{r d}\right)$

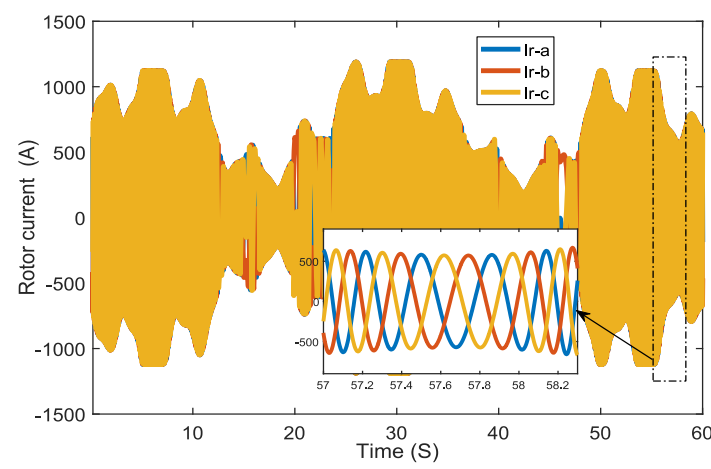

Figure.15 Rotor currents $I_{r a}, I_{r b}$, and $I_{r c}$

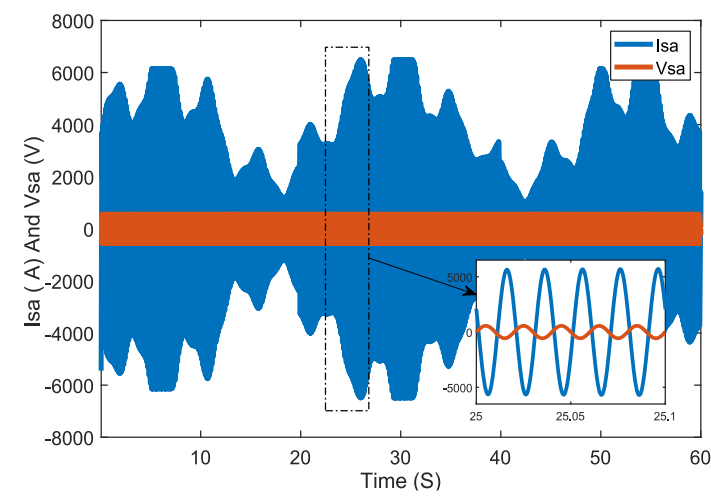

Figure.16 Stator currents $I_{s a}$ and stator voltage $V_{s a}$

Fig. 16 presents the voltage and current $I_{s a}, V_{s a}$ of a phase of the grid. The voltage and the current are in phase opposition which means that the active power is injected into the grid and that the power factor is unitary.

\section{Conclusion}

Takagi-Sugeno Fuzzy controller model is applied to the variable-speed wind energy conversion system based on the DFI-generator. In fact, this work focusses on the wind turbine control by designing Pitch control and the MPPT technique as well. This latter has shown its aptitude to extract the maximum
Table 1. Turbine parameters

\begin{tabular}{|l|c|}
\hline \multicolumn{1}{|c|}{ Designation } & Value \\
\hline Radius of the blades & $45 \mathrm{~m}$ \\
\hline Gear ratio & 100 \\
\hline Total Inertia & $254 \mathrm{Kg} \cdot \mathrm{m}^{2}$ \\
\hline Friction coefficient & 0.24 \\
\hline
\end{tabular}

Table 2. DFIG parameters

\begin{tabular}{|l|c|}
\hline \multicolumn{1}{|c|}{ Designation } & Value \\
\hline Rated Power & $3 \mathrm{MW}$ \\
\hline Frequency & $50 \mathrm{~Hz}$ \\
\hline Stator voltage & $690 \mathrm{~V}$ \\
\hline Stator resistance & $2.97 \mathrm{~m} \Omega$ \\
\hline Stator inductance & $12.241 \mathrm{mH}$ \\
\hline Rotor resistance & $3.82 \mathrm{~m} \Omega$ \\
\hline Rotor inductance & $12.177 \mathrm{mH}$ \\
\hline Mutual inductance & $12.12 \mathrm{mH}$ \\
\hline Number of pole pairs & 2 \\
\hline
\end{tabular}

Table 3. ADRC and PI controllers parameters

\begin{tabular}{|c|c|}
\hline \multicolumn{2}{|c|}{ ADRC Controller } \\
\hline Controller gain & $K_{p}=S_{C L}=270$ \\
\hline Pole of ESO & $S_{E S O}=5 S_{C L}=1350$ \\
\hline $\begin{array}{c}\text { Extended state } \\
\text { observer } \\
\text { gains (ESO) }\end{array}$ & $\begin{array}{c}\beta_{1}=-2 S_{E S O}=-2700 \\
\beta_{2}=\left(S_{E S O}\right)^{2}=1822500\end{array}$ \\
\hline Parameter gain & $b_{0}=6707.8$ \\
\hline PI Controller \\
\hline Gain of PI & $K_{p}=70.10^{7}$ \\
\hline Gain of PI & $K_{i}=5.10^{3}$ \\
\hline
\end{tabular}

available power by controlling the rotor speed and limiting the power at its nominal value. Moreover, this work presents the generator side converter control that is the DFI-generator's active and reactive power control. Indeed, this control is made by acting on the rotor currents with the help of the TakagiSugeno Fuzzy model designed.

In order to prove the proposed control strategy effectiveness and the system stability, a numerical simulation is carried out in Matlab software by comparing the proposed controller to the conventional PI controller and ADRC controller. Thus, the results have shown that the tracking performances of the proposed controller are better than these two controllers. In fact, the PI controller makes a considerable error, the ADRC makes an overshoot during small laps of time with zero-static error, while the proposed controller is more performant, it can track the reference signal without any error or overshoot. Moreover, the proposed controller is robust against the internal parameters' 
changes and rapid changes of the signal reference. Thus, this controller can work properly instead of the PI and ADRC controllers.

The main aim of the future work will be focussed on the electrical grid side control, by designing the new Takagi-Sugeno Fuzzy Model dedicated for this purpose. Also, the second aim is to implement the proposed controller on the external board by testing its performances in real-time.

\section{References}

[1] M. Mokhlis and M. Ferfra, " Optimization of Photovoltaic Panels Efficiency Using a Backstepping Control Technique Under Partial Shading Conditions", International Review on Modelling and Simulations, Vol.10, No.6, December 2017.

[2] K. A. Naik, C. P. Gupta, and E. Fernandez, "Design and implementation of interval type-2 fuzzy logic-PI based adaptive controller for DFIG based wind energy system", International Journal of Electrical Power \& Energy Systems, Vol.115, 2020.

[3] O. Zamzoum, Y. El Mourabit, M. Errouha, A. Derouich, and A. El Ghzizal, "Power control of variable speed wind turbine based on doubly fed induction generator using indirect field-oriented control with fuzzy logic controllers for performance optimization", Energy Science \& Engineering, Vol.6, pp.408-423, 2018.

[4] O. Belounis and H. Labar, "Fuzzy Sliding Mode Controller of DFIG for Wind Energy Conversion", International Journal of Intelligent Engineering and Systems, Vol.10, No.2, pp.163174, 2017.

[5] R. Sitharthan, M. Karthikeyan, D. Shanmuga Sundar, and S. Rajasekaran, "Adaptive hybrid intelligent MPPT controller to approximate effectual wind speed and optimal rotor speed of variable speed wind turbine", ISA Transactions, 2019.

[6] H. Liu, Y. Pan, S. Li, and Y. Chen, "Adaptive Fuzzy Backstepping Control of Fractional-Order Nonlinear Systems", IEEE Transactions on Systems, Man, and Cybernetics: Systems, Vol.47, No. 8, pp. 2209-2217, 2017.

[7] A. Bektache and B. Boukhezzar, "Nonlinear predictive control of a DFIG-based wind turbine for power capture optimization", International Journal of Electrical Power \& Energy Systems, Vol.101, pp.92-102, 2018.

[8] M. Chakib, T. Nasser, and A. Essadki, "Comparative Study of Active Disturbance Rejection Control with RST Control for Variable
Wind Speed Turbine Based on Doubly Fed Induction Generator Connected to the Grid", International Journal of Intelligent Engineering and Systems, Vol.13, No.1, 2020, pp.248-258, 2020.

[9] S. Li, H. Wang, A. Aitouche, and N. Christov, "Active fault tolerant control of wind turbine systems based on DFIG with actuator fault and disturbance using Takagi-Sugeno fuzzy model", Journal of the Franklin Institute, Vol.355, No.16, pp.8194-8212, 2018.

[10] F. Abdelmalki and N. Ouaaline, "The Fuzzy Tracking Control of Output vector of Double Fed Induction Generator DFIG via T-S Fuzzy Model", International Journal of Intelligent Engineering and Systems, Vol.11, No.1, pp.113121, 2018.

[11] S. Abdelmalek, A. Taher Azar, and D. Dib, "A Novel Actuator Fault-tolerant Control Strategy of DFIG-based Wind Turbines Using TakagiSugeno Multiple Models", International Journal of Control, Automation and Systems, Vol.16, No.3, pp.1415-1424, 2018.

[12] Y. Berrada, A. El Bakri, and I. Boumhidi, "Feedback T-S fuzzy controller in finite frequency for wind energy conversion systems based on neural network", In: Proc of Intelligent Systems and Computer Vision, pp. 1-6, 2017.

[13] Z. Civelek, "Optimization of fuzzy logic (Takagi-Sugeno) blade pitch angle controller in wind turbines by genetic algorithm", Engineering Science and Technology, an International Journal, 2019.

[14] S. Li, H. Wang, and A. Aitouche, "Active fault tolerant control of wind turbine systems based on DFIG with actuator fault and disturbance using Takagi-Sugeno fuzzy model", Journal of the Franklin Institute, Vol.355, No.16, pp.81948212, 2018. 